\title{
Characterization of the binding sites of the anticancer ruthenium(III) complexes KP1019 and KP1339 on human serum albumin via competition studies
}

\author{
Orsolya Dömötör · Christian G. Hartinger • Anna K. Bytzek • Tamás Kiss • Bernhard K. \\ Keppler · Eva A. Enyedy
}

\begin{abstract}
Indazolium trans-[tetrachloridobis(1H-indazole)ruthenate(III)] (KP1019) and its $\mathrm{Na}^{+}$ analogue (KP1339) are two of the most prominent non-platinum antitumor metal complexes currently undergoing clinical trials. After intravenous administration, they are known to bind to human serum albumin (HSA) in a non-covalent manner. In order to elucidate their HSA binding sites, displacement reactions with the established site markers warfarin and dansylglycine as well as bilirubin were monitored by spectrofluorimetry, ultrafiltration-UV-vis spectrophotometry and/or capillary zone electrophoresis. Conditional stability constants for the binding of KP1019 and KP1339 to sites I and II of HSA were determined, indicating that both $\mathrm{Ru}(\mathrm{III})$ compounds bind into both sites with moderately to strong affinity $\left(\log K_{1}{ }^{\prime}=5.3-5.8\right)$. No preference for either binding site was found and similar results were obtained for both metal complexes, demonstrating low influence of the counter ion on the binding event.
\end{abstract}

\section{Electronic supplementary material}

Orsolya Dömötör · Eva A. Enyedy $(\bowtie)$

Department of Inorganic and Analytical Chemistry, University of Szeged, Dóm tér 7. H-6720 Szeged, Hungary enyedy@chem.u-szeged.hu

Christian G. Hartinger $(\bowtie)$

The University of Auckland, School of Chemical Sciences, Private Bag 92019, Auckland 1142, New Zealand Institute of Inorganic Chemistry, University of Vienna, Waehringer Str. 42, A-1090 Vienna, Austria c.hartinger@auckland.ac.nz

Anna K. Bytzek · Bernhard K. Keppler

Institute of Inorganic Chemistry, University of Vienna, Waehringer Str. 42, A-1090 Vienna, Austria

Tamás Kiss

Department of Inorganic and Analytical Chemistry, University of Szeged, Dóm tér 7. H-6720 Szeged, Hungary Bioinorganic Chemistry Research Group of the Hungarian Academy of Sciences, University of Szeged, Dóm tér 7. H-6720 Szeged, Hungary 
Keywords Solution Equilibrium · Albumin B Binding Affinity $\cdot$ Fluorescence $\cdot$ Ruthenium Anticancer Agents $\cdot$ Site Markers

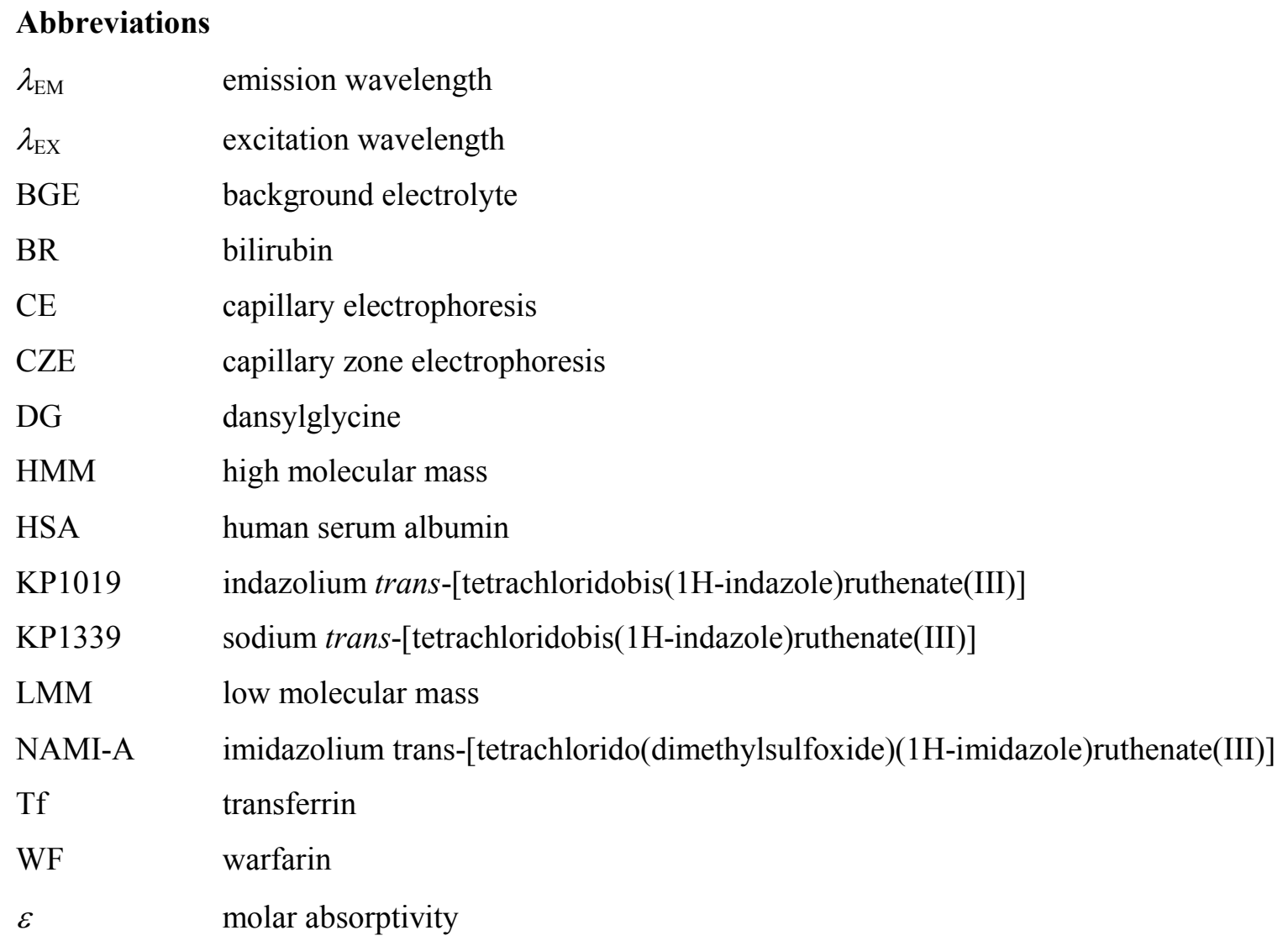




\section{Introduction}

The field of the metal-based anticancer drugs was initiated by cisplatin, one of the leading agents in the clinical use [1]. Ruthenium compounds are currently considered the most likely candidates for the next generation of metal-based anticancer drugs [2,3]. Two representatives of this class of compounds have entered clinical trials so far: imidazolium trans[tetrachlorido(dimethylsulfoxide)(1H-imidazole)ruthenate(III)] (NAMI-A) [4,5] and indazolium trans-[tetrachloridobis(1H-indazole)ruthenate(III)] (KP1019) [6-8] (see Chart 1 for structures). Only very moderate toxicities were observed in the case of KP1019 [6,7,9] whereas NAMI-A treatment was accompanied by painful blister formation at higher dosage, however that is actually higher than the advised dosage [10].

\section{Chart 1}

KP1019 shows remarkable antineoplastic activity against a wide number of preclinical tumor models, including cisplatin resistant colorectal tumors and some primary explanted human tumors $[2,6,11,12]$. Although the pharmacological target for antitumor ruthenium compounds has not been unequivocally identified, it is unlikely that their modes of action are similar to that of cisplatin [7]. The limitation in the application of KP1019 in the clinics was the low solubility and therefore, the maximum tolerated dose was not reachable in clinical trials [8]. According to the clinical study the maximum plasma level was about $0.3 \mathrm{mM}$ for KP1019 [8]. This problem was solved by the replacement of the indazolium counter ion by sodium (KP1339, Chart 1). KP1339 has a significantly better water solubility compared to KP1019 and participates in an ongoing clinical trial.

The minor side effects of the $\mathrm{Ru}(\mathrm{III})$ compounds may be related to their mode of action. After intravenous administration the complex binds to highly abundant serum proteins such as human serum albumin (HSA) and transferrin (Tf) [13-15]. The selective tumor targeting can be realized by the enhanced permeability and retention effect of the tumor tissue, and by the overexpression of transferrin receptors on cancer cells [16]. A further reason for their selectivity is the insufficient formation of new blood vessels in rapidly growing tumors that results in a more reductive environment as compared to normal tissue and facilitates $\mathrm{Ru}(\mathrm{III})$ reduction to $\mathrm{Ru}(\mathrm{II})$ ("activation by reduction" hypothesis) [17-19] and therefore ligand exchange and coordination towards biological targets such as DNA or proteins $[7,12,20]$. 
Therefore, reactions of anticancer metallodrugs with proteins are of considerable interest as these interactions might feature processes that are crucial for the biodistribution, the toxicity and even the mechanism of action of this important group of anticancer agents. KP1019 is known to bind to a large degree to HSA, which is suggested to act as a ruthenium reservoir $[15,21,22]$. HSA is the most abundant of the blood serum proteins occurring to the extent of $0.63 \mathrm{mM}$. It contributes to colloid osmotic pressure and is chiefly responsible for the maintenance of blood $\mathrm{pH}$. The protein serves as a transport vehicle for a wide variety of ligands, including fatty acids, bilirubin, steroids, metal ions, and various pharmaceuticals. It comprises a single chain with 585 amino acids organized in three similar domains (I, II, and III), each consisting of two subdomains (IA, IB, etc.). The principal regions of ligand binding sites of albumin are located in hydrophobic cavities in subdomains IIA and IIIA (sites I and II) [23-25]. A typical site marker for site I is the anticoagulant drug warfarin (WF) [26-29], while dansylglycine (DG) shows specificity for site II (see Fig. S1) [30-32]. Initial rapid binding of KP1019 takes place in a non-covalent manner at the hydrophobic binding sites of HSA, however after a longer incubation time the type of the interaction is converted slowly to a protein-coordinated form [33]. Similar behavior of NAMI-A and its pyridine analogues was found recently based on mainly electron paramagnetic resonance spectroscopic measurements [34,35]. A binding ratio of four KP1019 complex anions on a single HSA molecule was determined by $\mathrm{CD}$ and confirmed by inductively coupled plasma atomic emission spectroscopic (ICP-AES) method [23]. More recently, the KP1019-HSA association constants were determined by means of capillary electrophoresis (CE) as $9.9 \times 10^{3} \mathrm{M}^{-1}$, and by CE coupled to ICP-mass spectrometry (MS) as $1.06 \times 10^{4} \mathrm{M}^{-1}[13,21]$. It is noteworthy that separation methods such as CE may shift the chemical equilibrium of a reaction mixture and therefore spectroscopic methods provide a better means to investigate binding constants. Furthermore, the actual binding sites of KP1019 on HSA remain elusive. Herein we report on displacement experiments with well-established site markers for sites I and II and with the heme metabolite bilirubin (BR, Fig. S1), which is also transported by HSA and has relevance for patients with hyperbilirubinaemia [36], by means of spectroscopic and separation methods.

\section{Results and discussion}


$\mathrm{Ru}(\mathrm{III})$ complexes are known to undergo hydrolysis in aqueous solution [37,38], with the kinetics being dependent on the $\mathrm{pH}$ and the chloride concentration in the incubation medium [37]. Human plasma has a pH of about 7.4 and the chloride concentration is $104 \mathrm{mM}$. In order to suppress the hydrolysis to a wide extent, a chloride concentration of $150 \mathrm{mM}$ was chosen in our experiments and the incubations were done in $20 \mathrm{mM}$ phosphate buffer ( $\mathrm{pH} 7.40)$. This approach was successful for other anticancer agents like cisplatin and $\mathrm{Ru}(\mathrm{II})$-arene complexes [39-42]. However, the chloride/water exchange in the KP1019 and KP1339 is not suppressed completely within a $1 \mathrm{~h}$ interval under this condition $\left(25^{\circ} \mathrm{C}, \mathrm{pH} 7.40,150 \mathrm{mM} \mathrm{Cl}^{-}\right)$(Fig. S2), and especially in the case of KP1019 a higher extent of aquation takes place (after $1 \mathrm{~h} \sim 9 \%$ ).

It is noteworthy that the recovery of the HSA from the human blood and its dissolution in water and use under aerobic condition can easily lead to the oxidation of the free thiol group of the cysteine-34 residue. Thus, HSA is most probably at least partially present in the dimeric form. The dimerization may alter the binding capacities [43] but as the level of dimerization is unknown, the average binding capacity of the monomeric and dimeric HSA were calculated.

Initially, the conditional stability constants for the reaction of the $\mathrm{Ru}(\mathrm{III})$ complexes KP1019 and KP1339 to HSA were determined by means of fluorescence spectroscopy. HSA contains a single tryptophan (Trp214) residue that is responsible for the majority of the intrinsic fluorescence of the protein. Upon excitation at $295 \mathrm{~nm}$, HSA emits strong fluorescence at $350 \mathrm{~nm}$ which can be attenuated by a binding event at or close to the Trp214 due to its susceptibility to changes in its environment. Addition of KP1339 to HSA quenches its fluorescence very efficiently (Fig. 1), indicating that the conformation of the hydrophobic binding pocket in site I is significantly affected by the $\mathrm{Ru}(\mathrm{III})$ complex binding. Because selfabsorption of these complexes is significant at the wavelength range of the quenching measurements and would interfere with modeling (Table 1), a correction equation was applied to minimize this effect (see section Materials and methods/Spectrofluorimetric measurements). Trynda-Lemiesz and coworkers also observed the quenching of the emission of Trp by KP1019 [22], however under the conditions applied, the samples show high absorbance and no binding data was reported. The conditional stability constants calculated using the Stern-Volmer approach for KP1339 at a chosen $\lambda_{\mathrm{EM}}$ (inset of Fig. 1.b) and with PSEQUAD [44] for both complexes using the whole spectra were found to be similar (Table 1). Graphical solutions such as the Stern-Volmer plot, which is widely used in the literature $[45,46]$, cannot be applied in the emission wavelength range if the ligand has a significant 
intrinsic emission, such as the indazolium counter cation in KP1019 at $\lambda_{\mathrm{EX}}=295 \mathrm{~nm}$ (see Figs. S3 and S4; KP1339 is not fluorescent). Experiments to elucidate the role of the indazolium ion in the binding of KP1019 and HSA, revealed only weak binding of indazole to site II, and no binding to site I. Other critical point of the Stern-Volmer approach is that the substitution of the equilibrium concentrations by analytical concentrations in the formula may not provide trustable stability constants. The conditional binding constants $\log K^{\prime}$ under these conditions were computed from the quenching studies as 4.69(6) and 5.66(6) for KP1339 and KP1019, respectively. This big difference between the two binding constants has no reasonable chemical explanation, there are methodological uncertainties. In order to elucidate the problem the direct interaction between HSA and complexes KP1019 and KP1339 was also be followed by ultrafiltration quantification measurements with UV-vis spectrophotometric quantification.

Fig. 1

\section{Table 1}

It is noteworthy that ultrafiltration might induce release of weakly surface bound ligands. In this setup, the non-bound fraction was separated from HSA and the [HSA-Ru(III) complex] by ultrafiltration with a $10 \mathrm{kDa}$ cut-off membrane filter resulting in low (LMM) and high molecular mass (HMM) fractions. The LMM samples were analyzed by UV-vis spectroscopy and compared to reference spectra (see Fig. S5 for the HSA-KP1339 system), yielding the ratios of the non-bound and total amount of the compounds. From these data pairs, the stoichiometry and conditional stability constants of the HSA complexes were calculated (Fig. 2 and Table 1). This method allows the determination of stepwise stability constants, while spectrofluorimetry can only be used for the first step because of the highly diluted samples resulting in strong dissociation. Comparing the $\log K^{\prime}{ }_{1}$ values calculated by the different methods it can be seen that ultrafiltration-UV-vis gave somewhat lower values than spectrofluorimetry. The main reason is probably the different experimental conditions of the methods used: interference in the equilibrium during the separation process in ultrafiltration and $\mu \mathrm{M}$ concentrations at spectrofluorimetry, and $\mathrm{mM}$ concentrations at ultrafiltration in the quantification process.

Fig. 2

In recent years, researchers have become interested in determining the binding sites of metallodrugs on biomolecules for improved design of next generation drug candidates. It is known that KP1019 binds to HSA initially in a non-covalent manner then the coordination of 
histidine nitrogen(s) to the $\mathrm{Ru}(\mathrm{III})$ centre takes place [33]. The spectrofluorimetric quenching studies and the ultrafiltration (vide supra) cannot give information about the feature of the binding mode whether it is non-covalent or coordinative. In order to get a deeper insight into the binding event, a strategy involving particular site markers was applied to probe the nature of the preferred binding site, as well as the specificity and affinity towards the protein.

Warfarin, bilirubin were used as site markers for site I, and dansylglycine for site II; and Fig. 3 demonstrates that these compounds have a weak or negligible molar fluorescence emission at the given excitation wavelengths. The addition of HSA induced an increase in intensity due to the binding of these compounds to the respective site on the protein. Based on the molar fluorescence spectra, which are only valid under the conditions and instrument settings applied, stability constants were calculated using PSEQUAD [44]. The conditional HSA binding constants ( $\left.\log K^{\prime}\right)$ for WF, BR and DG are comparable with data obtained by us and others $[26-32,36,47,48]$ (Table $\mathrm{S} 1$ ) and are found to be practically temperature independent $\left(25^{\circ} \mathrm{C} v s .37^{\circ} \mathrm{C}\right)$ within the uncertainty of the measurement. The calculations for BR required application of a self-absorbance correction because of its considerable absorbance at the excitation wavelength. However, the Ru(III) complexes and their HSA adducts [HSA-Ru(III) complex] have no intrinsic emission in this wavelength range.

Fig. 3

The HSA-site marker adducts [HSA-WF], [HSA-BR] and [HSA-DG] emit intensively and their displacement by other ligands from the binding pocket of the protein is accompanied by a considerable decrease in the emission intensity. Therefore, the displacement of the site markers at various concentrations of the $\mathrm{Ru}(\mathrm{III})$ complexes could be followed via intensity changes of the emission spectra. In case of the HSA-WF-KP1339 system, the initial intensity decreased by about $50 \%$ upon addition of an 8 -fold excess of the $\mathrm{Ru}$ (III) complex (Fig. 4) accompanied by a bathochromic shift, which can be attributed to the increasing free WF fraction and its higher emission maximum. Similar results were obtained for the reaction of KP1019 and [HSA-WF] and the binding constants calculated from WF displacement and quenching measurements (Table 1) are in good agreement.

Fig. 4

The displacement reactions of BR and DG displayed a similar trend as found for WF (for DG see Fig. 5) and no significant difference for KP1019 and KP1339 was observed (for the conditional stability constants see Table 1). Based on these data it can be concluded that the nature of the counter ion does not affect the ability of the trans-[tetrachloridobis $(1 \mathrm{H}-$ 
indazole)ruthenate(III)] anion to interact with HSA. However, in the case of KP1339 the constant derived from the quenching experiments is one order of magnitude lower than from WF displacement, whereas in case of KP1019 similar results were obtained. Although it can happen that a small portion of the KP1339 loses the axial indazole ligand and since the free ligand exhibit an extremely strong emission at $295 \mathrm{~nm}$ excitation wavelength, it can cause a lower quenching of the HSA fluorescence. It is noteworthy that the displacement of WF and BR by KP1019 was also observed previously; however no quantitative data evaluation was performed [22].

Fig. 5

In addition to the spectroscopic studies, the reactions of [HSA-Ru(III) complex] with WF and DG were studied by capillary zone electrophoresis (CZE)-UV-vis and ultrafiltration-UV-vis methods (BR could not be studied because of its low aqueous solubility and extinction coefficient). CE has been used to determine chemical equilibria in proteinmetallodrug systems $[49,50]$. Compared with other separation-based assays such as highperformance liquid chromatography (HPLC), CE possesses distinctive advantages such as shorter analysis time, use of electrolyte compositions compatible with physiological incubation conditions, and no stationary phase involved in separation [51]. A similar approach as in the spectroscopic studies was followed with the HSA-to-site marker ratio kept constant and the KP1019 and KP1339 content was varied. No interaction between the Ru(III) compounds and the site markers were detected by CZE under the applied conditions and a linear concentration-peak height correlation was observed for the metal complexes (Fig.s S6 and S7). The data were analyzed based on the increase of the peak heights belonging to the released site markers as a result of their displacement by the Ru(III) complexes [48]. Fig. 6 shows the displacement of WF by the Ru(III) complexes monitored by CZE. The increasing amount of the non-bound site marker with increasing metal complex concentration confirms that these complexes tend to compete for the HSA binding sites with WF; and the same tendency is observed in the case of DG. Moreover, an 8-fold excess of the complexes was sufficient to complete the displacement of the site markers at 1:1 site marker-to-HSA ratio. Again, very similar behavior for the two Ru(III) complexes has been observed with the ultrafiltration displacement approach. Analysis of the LMM fraction by spectrofluorimetry and UV-vis method revealed an increasing quantity of non-bound site marker with higher metal complex concentration (see Fig. S8). This indicates that both KP1339 and KP1019 are 
able to compete with WF and DG for the respective HSA binding sites with similar binding strength and to a similar extent.

Fig. 6

An important feature for the clinical application of such drug compounds may be the fact that both $\mathrm{Ru}$ (III) complexes can displace BR from HSA (Fig. 7). The unbound fraction of $\mathrm{Ru}(\mathrm{III})$ complex calculated on the basis of the stability constants (Table 1) is increased at higher concentrations of BR in a hypothetical system containing $630 \mu \mathrm{M}$ HSA (according to its physiological serum concentration) and equimolar KP1339, i.e., an increase of the BR concentration from 11 up to $68 \mu \mathrm{M}$ causes a significant 2.5-fold increase in the free, unbound fraction of the $\mathrm{Ru}$ (III) complexes (Fig. 8). It is noteworthy that all the BR is bound to HSA under this condition, and no BR displacement takes place by the $\mathrm{Ru}(\mathrm{III})$ complex. Generally the free portion of a drug can reach the final target, hence is responsible for the biological effect, while HSA has a temporarily reservoir role [52,53]. Taking into account that patients with liver malfunctions have higher bilirubin levels, this result may be of significance for their treatment with such $\mathrm{Ru}(\mathrm{III})$ complexes.

Fig. 7

Fig. 8

\section{Conclusions}

It is essential to explore the interactions of anticancer metallodrugs with serum proteins as these interactions might feature processes that are crucial for biodistribution, toxicity and even their mechanism of action. Human serum albumin is the most abundant plasma protein and responsible for the binding and transport of numerous molecules including metal complexes. The characterization of the binding of the Ru(III) complexes KP1339 and KP1019 to albumin and the determination of the preferred binding sites were performed as this protein is considered as their primary binding partner after intravenous administration.

A panel of methods comprising spectrofluorimetry, CZE-UV-vis and ultrafiltration-UV-vis was used to investigate the interaction between HSA and KP1019 and KP1339. Using warfarin, bilirubin and dansylglycine as site markers, the preferred binding sites for these novel chemotherapeutics were determined by displacement experiments. Considerable displacement of all site markers takes place upon addition of both $\mathrm{Ru}(\mathrm{III})$ compounds demonstrating their ability to bind to both sites I and II of albumin. No significant differences 
were found in the binding ability at these binding sites based on the spectrofluorimetric measurements; and both compounds KP1019 and KP1339 are able bind into both sites with moderately strong affinity. Therefore, the counter ion does not affect the binding of trans[tetrachloridobis(1H-indazole)ruthenate(III)] anions to albumin. CZE-UV-vis and ultrafiltration-UV-vis measurements could also confirm the results of the spectrofluorimetric experiments. A result of clinical relevance is the finding that KP1339 and KP1019 are able to compete with BR for its binding site under physiological condition and may affect the treatment of patients with elevated bilirubin levels.

\section{Materials and methods}

Chemicals

KP1019, KP1339, racemic WF, DG, BR, HSA (as lyophilized powder with fatty acids, A1653), $\mathrm{NaH}_{2} \mathrm{PO}_{4}, \mathrm{Na}_{2} \mathrm{HPO}_{4}$ and $\mathrm{NaCl}$ were obtained from Sigma-Aldrich in puriss quality. Doubly distilled Milli-Q water was used for sample preparations.

HSA solution was freshly prepared before the experiments and its concentration was estimated from its UV absorption: $\varepsilon_{280} \mathrm{~nm}(\mathrm{HSA})=36850 \mathrm{M}^{-1} \mathrm{~cm}^{-1}$ [54]. Solutions of WF, DG and $\mathrm{BR}$ were prepared prior to the analyses with one equivalent of $\mathrm{NaOH}$ and their concentrations were calculated on the basis of their UV-vis spectra: $\varepsilon_{308} \mathrm{~nm}(\mathrm{WF})=14475$ $\mathrm{M}^{-1} \mathrm{~cm}^{-1}, \varepsilon_{327 \mathrm{~nm}}(\mathrm{DG})=5068 \mathrm{M}^{-1} \mathrm{~cm}^{-1}, \varepsilon_{438 \mathrm{~nm}}(\mathrm{BR})=37950 \mathrm{M}^{-1} \mathrm{~cm}^{-1}$.

Spectrofluorimetric measurements

Fluorescence spectra were recorded on a Hitachi-F4500 fluorimeter using $5 \mathrm{~nm} / 5 \mathrm{~nm}$ slit width in $1 \mathrm{~cm}$ quartz cell at $25.0 \pm 0.1^{\circ} \mathrm{C}$. All solutions were prepared in $20 \mathrm{mM}$ phosphate buffer (pH 7.40) containing $150 \mathrm{mM} \mathrm{M} \mathrm{NaCl}$ and were incubated for $15 \mathrm{~min}$. Samples usually contained $1 \mu \mathrm{M}$ HSA (10 $\mu \mathrm{M}$ HSA in BR displacement experiments) and various HSA-toligand ratios (from 1:0 to 1:20) were used. In the site marker displacement experiments the HSA-to-site marker (WF, DG or BR) ratio was 1:1 and the concentration of the $\mathrm{Ru}(\mathrm{III})$ complexes was varied. Spectra were recorded after $10 \mathrm{~min}$ incubations. BR-containing samples were kept in the dark. The excitation wavelengths were 295, 310, 335 or $487 \mathrm{~nm}$ depending on the type of the experiment and the emission was read in the range of 310-650 
$\mathrm{nm}$ (see Table S2 for details). The conditional binding constants were calculated with the computer program PSEQUAD [44] and quenching data were for comparison purposes also analyzed by Stern-Volmer plots (see SI) $[45,46]$.

Three-dimensional spectra were recorded at 210-500 nm excitation and 230-650 nm emission wavelengths.

A correction for self-absorbance was necessary in the quenching experiments because fluorescence is significantly absorbed by the $\mathrm{Ru}(\mathrm{III})$ complexes. Samples containing BR also had to be corrected (for the molar absorption spectra of KP1339 and BR see Fig. S9). The correction was carried out according to the equation:

$$
F_{\text {corrected }}=F_{\text {measured }} \times 10^{(A(E X)+A(E M)) / 2}
$$

where $F_{\text {corrected }}$ and $F_{\text {measured }}$ are the corrected and measured fluorescence intensities, and $A(E X)$ and $A(E M)$ are the absorptivities at the excitation and emission wavelengths in the samples, respectively. The inner filter effect in the case of other titrations was negligible and therefore no corrections were applied.

Membrane ultrafiltration-UV-vis measurements

Samples were separated by ultrafiltration through $10 \mathrm{kDa}$ membrane filters (Microcon YM-10 centrifugal filter unit, Millipore) in low (LMM) and high molecular mass (HMM) fractions with the help of a temperature controlled centrifuge (Sanyo, 10000/s, $10 \mathrm{~min}$ ). The samples $(0.50 \mathrm{~mL}$ ) contained $60 \mu \mathrm{M}$ HSA and the metal complexes (from 10 to $150 \mu \mathrm{M}$ ) in $20 \mathrm{mM}$ phosphate buffer $\left(150 \mathrm{mM} \mathrm{NaCl}\right.$; $\mathrm{pH} 7.40$ at $\left.25.0 \pm 0.1^{\circ} \mathrm{C}\right)$ and were incubated for $15 \mathrm{~min}$. In the site marker displacement experiments the HSA-to-site marker ratio was 1:1 and the concentration of the $\mathrm{Ru}(\mathrm{III})$ complexes was varied (from 10 to $180 \mu \mathrm{M}$ ). The LMM fraction containing the non-bound metal complex was separated from HSA and [HSA-KP1019] (or [HSA-KP1339]) adducts in the HMM fraction. The LMM fractions were diluted to $1.00 \mathrm{~mL}$ and the concentration of the non-bound complex was determined by UV-vis spectrophotometry and in the case of competition measurements by spectrofluorimetry (according to the site marker, see details in Table S2 and Fig. S10). The UV-vis spectra of the LMM fractions were compared with the reference spectra of the samples containing KP1019 or KP1339 without the protein at the concentration equal to that in the ultrafiltered samples. A Hewlett Packard 8452A spectrophotometer was used to record the spectra in the region of $200-700 \mathrm{~nm}$ at $25^{\circ} \mathrm{C}$ and a path length of $1 \mathrm{~cm}$. 
Stoichiometries and conditional binding constants $\left(\log \beta^{\prime}\right)$ were then calculated based on the equilibrium processes and mass-balance equations for the components (see SI) were established with the computer program PSEQUAD [44] from the total and protein-free concentration data pairs of the ligands obtained at different protein-to-Ru(III) complex ratios; uncertainties in the stability constants are given in parentheses.

\section{CZE measurements}

CZE experiments were performed with an $\mathrm{HP}^{3 \mathrm{D}} \mathrm{CZE}$ system (Agilent Technologies). For all experiments capillaries of $48 \mathrm{~cm}$ total length (50 $\mu \mathrm{m}$ ID) were used (BGB Analytik AG). The detection was carried out by on-column UV photometric measurement in the range of 200$330 \mathrm{~nm}$. Injections were performed by applying a pressure of $30 \mathrm{mbar}$ for $5 \mathrm{~s}$, and constant voltages of $28 \mathrm{kV}$ were used for phosphate buffer at $\mathrm{pH} 7.40$ as background electrolyte (BGE). Prior to the first use, the capillary was flushed at 1 bar with $0.1 \mathrm{M} \mathrm{HCl}$, water, $0.1 \mathrm{M}$ $\mathrm{NaOH}$ and again with water (10 min each). Before each injection, the capillary was purged for $2 \mathrm{~min}$ both with water and the BGE followed by applying a voltage of $28 \mathrm{kV}$ for $30 \mathrm{~s}$ and flushed for $1 \mathrm{~min}$ with BGE again. The cleaning procedure included purging with $0.1 \mathrm{M} \mathrm{HCl}$, water and $0.1 \mathrm{M} \mathrm{NaOH}$ (each for $2 \mathrm{~min}$ ). The $\mathrm{CZE}$ data was recorded using the ChemStation software (HP, Agilent Technologies).

Samples containing $100 \mu \mathrm{M}$ HSA and the ligands (from 25 to $800 \mu \mathrm{M}$ ) in $20 \mathrm{mM}$ phosphate buffer $\left(150 \mathrm{mM} \mathrm{NaCl}\right.$; $\mathrm{pH} 7.40$ at $\left.25.0 \pm 0.1^{\circ} \mathrm{C}\right)$ were incubated for 40 min prior to the measurements. In the WF or DG displacement experiments the HSA-to-site marker ratio was 1:1 and the concentration of KP1019 or KP1339 was varied (from 25 to $800 \mu \mathrm{M}$ ). The peak height of the non-bound site marker was used in order to obtain its concentration employing external calibration.

Acknowledgments This work has been supported by the Hungarian Research Foundation OTKA K77833 and "TÁMOP-4.2.1/B-09/1/KONV-2010-0005 - Creating the Center of Excellence at the University of Szeged", cofinanced by the European Regional Fund. É.A. Enyedy gratefully acknowledges the financial support of J. Bolyai research fellowship. We thank the Austrian Science Fund (FWF; I496-B11), and COST D39 and CM0902 for financial support.

\section{References}


1. Jung Y, Lippard SJ (2007) Chem Rev 107:1387-1407

2. Galanski M, Arion VB, Jakupec MA, Keppler BK (2003) Curr Pharm Des 9:20782089

3. Dyson PJ, Sava G (2006) Dalton Trans 1929-1933

4. Sava G, Alessio E, Bergamo A, Mestroni G (1999) Top Biol Inorg Chem 1:143-169

5. Sava G, Capozzi I, Clerici K, Gagliardi G, Alessio E, Mestroni G (1998) Clin Exp Metastasis 16:371-379

6. Hartinger CG, Jakupec MA, Zorbas-Seifried S, Groessl M, Egger A, Berger W, Zorbas H, Dyson PJ, Keppler BK (2008) Chem Biodiversity 5:2140-2155

7. Hartinger CG, Zorbas-Seifried S, Jakupec MA, Kynast B, Zorbas H, Keppler BK (2006) J Inorg Chem 100:891-904

8. Lentz F, Drescher A, Lindauer A, Henke M, Hilger RA, Hartinger CG, Scheulen ME, Dittrich C, Keppler BK, Jaehde U (2009) Anticancer Drugs 20:97-103

9. Dittrich C, Scheulen ME, Jaehde U, Kynast B, Gneist M, Richly H, Schaad S, Arion VB, Keppler BK (2005) Proc Am Assoc Cancer Res 46:P472

10. Rademaker-Lakhai JM, Bongard D, Pluim D, Beijnen JH, Schellens JH (2004) Clin Cancer Res 10:3717-3727

11. Kapitza S, Pongratz M, Jakupec MA, Heffeter P, Berger W, Lackinger L, Keppler BK, Marian B (2005) J Cancer Res Clin Oncol 131:101-110

12. Kapitza S, Jakupec MA, Uhl M, Keppler BK, Marian B (2005) Cancer Lett 226:115121

13. Timerbaev AR, Rudnev AV, Semenova O, Hartinger CG, Keppler BK (2005) Anal Biochem 341:326-333

14. Sulyok M, Hann S, Hartinger CG, Keppler BK, Stingeder G, Koellensperger G (2005) J Anal At Spectrom 20:856-863

15. Groessl M, Hartinger CG, Polec-Pawlak K, Jarosz M, Keppler BK (2008) Electrophoresis 29:2224-2232

16. MacKenzie EL, Iwasaki K, Tsuji Y (2008) Antioxid Redox Signal 10:997-1030

17. Clarke MJ (2003) Coord Chem Rev 236:209-233

18. Jakupec MA, Reisner E, Eichinger A, Pongratz M, Arion VB, Galanski M, Hartinger CG, Keppler BK (2005) J Med Chem 48:2831-2837

19. Gatenby RA, Gillies RJ (2004) Nat Rev Cancer 4:891-899 
20. Brabec V, Novakova O (2006) Drug Resist Updat 9:111-122

21. Polec-Pawlak K, Abramski JK, Semenova O, Hartinger CG, Timerbaev AR, Keppler BK, Jarosz M (2006) Electrophoresis 27:1128-1135

22. Trynda-Lemiesz L, Karaczyn A, Keppler BK, Kozłowski H (2000) J Inorg Biochem 78:341-346

23. Carter DC, Ho JX (1994) Adv Protein Chem 45:153-204

24. Peters Jr T (1985) Adv Protein Chem 37:161-245

25. He XM, Carter DC (1992) Nature 358:209-215

26. Sudlow G, Birkett DJ, Wade DN (1975) Mol Pharmacol 11:824-832

27. Epps DE, Raub TJ, Kézdy FJ (1995) Anal Biochem 227:342-350

28. Pinkerton TC, Koeplinger KA (1990) Anal Chem 62:2114-2122

29. Buttar D, Colclough N, Gerhardt S, MacFaul PA, Phillips SD, Plowright A, Whittamore P, Tama K, Maskos K, Steinbacher S, Steuber H (2010) Bioorg Med Chem 18:7486-7496

30. Chignell CF (1969) Mol Pharmacol 5:244-252

31. Muller N, Lapicque F, Drelon E, Netter P (1994) J Pharm Pharmacol 46:300-304

32. Hutchinson JP, Oldham TC, El-Thaher TSH, Miller AD (1997) J Chem Soc Perkin Trans 2: 279-288

33. Cetinbas N, Webb MI, Dubland JA, Walsby CJ (2010) J Biol Inorg Chem 15:131-145

34. Webb MI, Walsby CJ (2011) Dalton Trans 40: 1322-1331

35. Webb MI, Chard RA, Al-Jobory YM, Jones MR, Wong EWY, Walsby CJ (2012) Inorg Chem 51: 954-966

36. Weisiger RA, Ostrow JD, Koehler RK, Webster CC, Mukerjee P, Pascolo L, Tiribelli C (2001) J Biol Chem 276:29953-29960

37. Pieper T, Peti W, Keppler BK (2000) Metal-Based Drugs 7:225-232.

38. Küng A, Pieper T, Wissiack R, Rosenberg E, Keppler BK (2001) J Biol Inorg Chem 6:292-299

39. Bertini I, Gray H, Stiefel E, Valentine J (2007) Biological Inorganic Chemistry: structure and reactivity; University Science Books, Sausalito, California

40. Clarke MJ (2002) Coord Chem Rev 232:69-93

41. Ang WH, Casini A, Sava G, Dyson PJ (2011) J Organomet Chem 696:989-998

42. Scolaro C, Hartinger CG, Allardyce CS, Keppler BK, Dyson PJ (2008) J Inorg Biochem 102:1743-1748 
43. Oettl K, Stauber RE (2007) British Journal of Pharmacology 151:580-590

44. Zékány L, Nagypál I (1985) Computational Methods for the Determination of Stability Constants, Leggett DL, Ed. Plenum Press, New York, pp 291-353

45. Lakowicz JR, Principles of Fluorescence Spectroscopy (2006) 3rd. Ed. Springer Science, New York

46. Valeur B (2001) Molecular Fluorescence Principles and Applications, Wiley-VCH $\mathrm{GmbH}$

47. Enyedy ÉA, Farkas E, Dömötör O, Santos MA (2011) J Inorg Biochem 105:326-335

48. Enyedy ÉA, Horváth L, Hetényi A, Tuccinardi T, Hartinger CG, Keppler BK, Kiss T (2011) Bioorg Med Chem 19:4202-4210.

49. Rudnev AV, Aleksenko SS, Semenova O, Hartinger CG, Timerbaev AR, Keppler BK (2005) J Sep Sci 28:121-127

50. Aleksenko SS, Hartinger CG, Semenova O, Meelich K, Timerbaev AR, Keppler BK (2007) J Chromatogr A 1155:218-221

51. Hartinger CG, Timerbaev AR, Keppler BK (2003) Electrophoresis 24:2023-2037

52. Peters T. (1996) All About Albumin: Biochemistry, Genetics and Medical Applications, Academic Press, San Diego

53. Fanali G, Masi A, Trezza V, Marino M., Fasano M, Ascenzi P (2012) Mol Aspects Med 33:209-290

54. Chasteen ND, Grady JK, Holloway CE (1986) Inorg Chem 25:2754-2760 


\section{Legends to figures}

Chart 1 Structures of the Ru(III) complexes KP1019= indazolium trans[tetrachloridobis $(1 \mathrm{H}$-indazole)ruthenate(III)]; KP1339 = sodium trans-[tetrachloridobis $(1 \mathrm{H}-$ indazole)ruthenate(III)]; NAMI-A = imidazolium trans-[tetrachlorido(dimethylsulfoxide)(1Himidazole)ruthenate(III)]

Fig. 1 Fluorescence emission spectra of HSA (dashed line) and the HSA-KP1339 system (solid lines) (a); changes of the emission intensities at $334 \mathrm{~nm}$ plotted against the concentration of KP1339 $(\diamond)$ with the Stern-Volmer plot at $334 \mathrm{~nm}$ as inset (b) $\left\{c_{\mathrm{HSA}}=1.0\right.$ $\mu \mathrm{M} ; c_{\mathrm{KP} 1339}=0-15 \mu \mathrm{M} ; \lambda_{\mathrm{EX}}=295 \mathrm{~nm} ; t=25^{\circ} \mathrm{C} ; \mathrm{pH}=7.40(20 \mathrm{mM}$ phosphate buffer; 150 $\mathrm{mM} \mathrm{NaCl}) ; \mathrm{PTM}=700 \mathrm{~V}$; Slits: $5 / 5 \mathrm{~nm}\}$.

Fig. 2 Equilibrium concentration of the bound KP1339 plotted against the ratio of HSA to KP1339 calculated from the UV-vis spectra of the ultrafiltered LMM fractions of HSA-KP1339 samples (for two parallel measurements: $\mathbf{n}, \square)$ together with the values based on the determined binding constants (dashed line) $\left\{c_{\mathrm{HSA}}=58 \mu \mathrm{M} ; t=25^{\circ} \mathrm{C} ; \mathrm{pH}=7.40(20\right.$ $\mathrm{mM}$ phosphate buffer; $150 \mathrm{mM} \mathrm{NaCl})\}$.

Fig 3 Molar fluorescence emission spectra of WF, [HSA-WF] $\left(\lambda_{\mathrm{EX}}=310 \mathrm{~nm}\right), \mathrm{DG}$, $[\mathrm{HSA}-\mathrm{DG}]\left(\lambda_{\mathrm{EX}}=335 \mathrm{~nm}\right)$ and $[\mathrm{HSA}-\mathrm{BR}]\left(\lambda_{\mathrm{EX}}=487 \mathrm{~nm}\right)\left\{t=25^{\circ} \mathrm{C} ; \mathrm{pH}=7.40(20 \mathrm{mM}\right.$ phosphate buffer; $150 \mathrm{mM} \mathrm{NaCl}$ ); PTM = $700 \mathrm{~V}$; Slits: 5/5 nm\}.

Fig. 4 Fluorescence emission spectra obtained by the titration of HSA-WF (1:1) with KP1339 $\left\{c_{\mathrm{HSA}}=c_{\mathrm{WF}}=1.0 \mu \mathrm{M} ; c_{\mathrm{KP} 1339}=0-18 \mu \mathrm{M} ; \lambda_{\mathrm{EX}}=310 \mathrm{~nm} ; t=25^{\circ} \mathrm{C} ; \mathrm{pH}=7.40(20 \mathrm{mM}\right.$ phosphate buffer; $150 \mathrm{mM} \mathrm{NaCl}$ ); PTM $=700 \mathrm{~V}$; Slits: $5 / 5 \mathrm{~nm}$ \}. The inset shows the fitting of the intensities at $390 \mathrm{~nm}$ between the measured ( $\boldsymbol{\square})$ and the calculated values (solid grey line) at various KP1339 concentrations.

Fig. 5 Changes of the emission intensities at $500 \mathrm{~nm}$ plotted against the concentration of KP1019 $(\diamond)$ and KP1339 $(\diamond)$ obtained by the titration of HSA-DG $(1: 1)$ with the Ru(III) complexes $\left\{c_{\mathrm{HSA}}=c_{\mathrm{DG}}=1.0 \mu \mathrm{M} ; \lambda_{\mathrm{EX}}=335 \mathrm{~nm} ; t=25^{\circ} \mathrm{C} ; \mathrm{pH}=7.40(20 \mathrm{mM}\right.$ phosphate buffer; $150 \mathrm{mM} \mathrm{NaCl}$ ); PTM = $700 \mathrm{~V}$; Slits: $5 / 5 \mathrm{~nm}\}$. 
Fig. 6 The non-bound WF detected by CZE depicted against the ratio of WF to KP1019 (O) or $\mathrm{KP} 1339(\bullet)$ in the HSA-WF-Ru(III) complex systems $\left\{c_{\mathrm{HSA}}=c_{\mathrm{WF}}=100 \mu \mathrm{M} ; t=37^{\circ} \mathrm{C} ; \mathrm{pH}\right.$ $=7.40(20 \mathrm{mM}$ phosphate buffer; $150 \mathrm{mM} \mathrm{NaCl}) ; \lambda=310 \mathrm{~nm}\}$.

Fig. 7 Changes of the emission intensities at $530 \mathrm{~nm}$ plotted against the concentration of KP1339 obtained by two parallel titrations of HSA-BR (1:1) with KP1339 (घ, $\square)$ together with the concentration distribution curves calculated for the system $\left\{c_{\mathrm{HSA}}=c_{\mathrm{BR}}=10 \mu \mathrm{M} ; \lambda_{\mathrm{EX}}\right.$ $=487 \mathrm{~nm} ; t=25{ }^{\circ} \mathrm{C} ; \mathrm{pH}=7.40(20 \mathrm{mM}$ phosphate buffer; $150 \mathrm{mM} \mathrm{NaCl}) ; \mathrm{PTM}=700 \mathrm{~V}$; Slits: $5 / 5 \mathrm{~nm}\}$.

Fig. 8 Molar fractions of the bound and non-bound $\mathrm{Ru}(\mathrm{III})$ complexes in a hypothetical HSA-BR-KP1339 system at various BR concentrations when $c_{\mathrm{HSA}}=c_{\mathrm{KP} 1339}=630 \mu \mathrm{M}$ and occupation of only one binding site is presumed \{[HSA-KP1339]: grey; non-bound KP1339: black . 


\section{Table 1}

Conditional binding constants ( $\left.\log K^{\prime}\right)$ and $K_{D}$ of the [HSA-Ru(III) complexes] calculated from the spectrofluorimetric and ultrafiltration-UV-vis measurements. ${ }^{a}$

KP1339 KP1019

\section{Quenching $^{\mathrm{b}}$}

$\log K^{\prime}($ PSEQUAD)

4.69(6)

$5.66(6)$

$K_{D}$ (PSEQUAD)

$20.4 \mu \mathrm{M}$

$2.2 \mu \mathrm{M}$

$\log K^{\prime}$ (Stern-Volmer)

4.66(6); (4.92(2)) ${ }^{\mathrm{e}}$

$K_{D}$ (Stern-Volmer) $21.9 \mu \mathrm{M} ;(12.0 \mu \mathrm{M})^{\mathrm{e}}$

Site marker displacement ${ }^{\mathrm{c}}$

$\log K^{\prime}(\mathrm{WF})$

$\log K^{\prime}(\mathrm{DG})$

$\log K^{\prime}(\mathrm{BR})$

$6.01(2)$

Ultrafiltration-UV-vis ${ }^{\mathrm{d}}$

$\log K^{\prime}{ }_{1}$

$\log K^{\prime}{ }_{2}$

4.67(5)

$4.6(2)$

\footnotetext{
${ }^{a}$ Standard deviations in parenthesis.

${ }^{\mathrm{b}}$ Determined by spectrofluorimetry; $\left\{c_{\mathrm{HSA}}=1 \mu \mathrm{M} ; t=25^{\circ} \mathrm{C} ; \mathrm{pH}=7.40(20 \mathrm{mM}\right.$ phosphate buffer, $150 \mathrm{mM} \mathrm{NaCl})\}$.

${ }^{\mathrm{c}}$ Determined by spectrofluorimetry; $\left\{c_{\mathrm{HSA}}=c_{\text {site marker }}=1 \mu \mathrm{M} ; t=25^{\circ} \mathrm{C} ; \mathrm{pH}=7.40(20\right.$ $\mathrm{mM}$ phosphate $150 \mathrm{mM} \mathrm{NaCl})\}$; For the $\log K^{\prime}$ values of the HSA-site marker complexes see Table S1.

${ }^{\mathrm{d}}$ Determined by ultrafiltration-UV-vis; $\left\{c_{\mathrm{HSA}}=60 \mu \mathrm{M} ; t=25^{\circ} \mathrm{C} ; \mathrm{pH}=7.40(20 \mathrm{mM}\right.$ phosphate buffer, $150 \mathrm{mM} \mathrm{NaCl}$ ) .

${ }^{\mathrm{e}}$ Values in the brackets give the result without applying self-absorbance correction.
} 

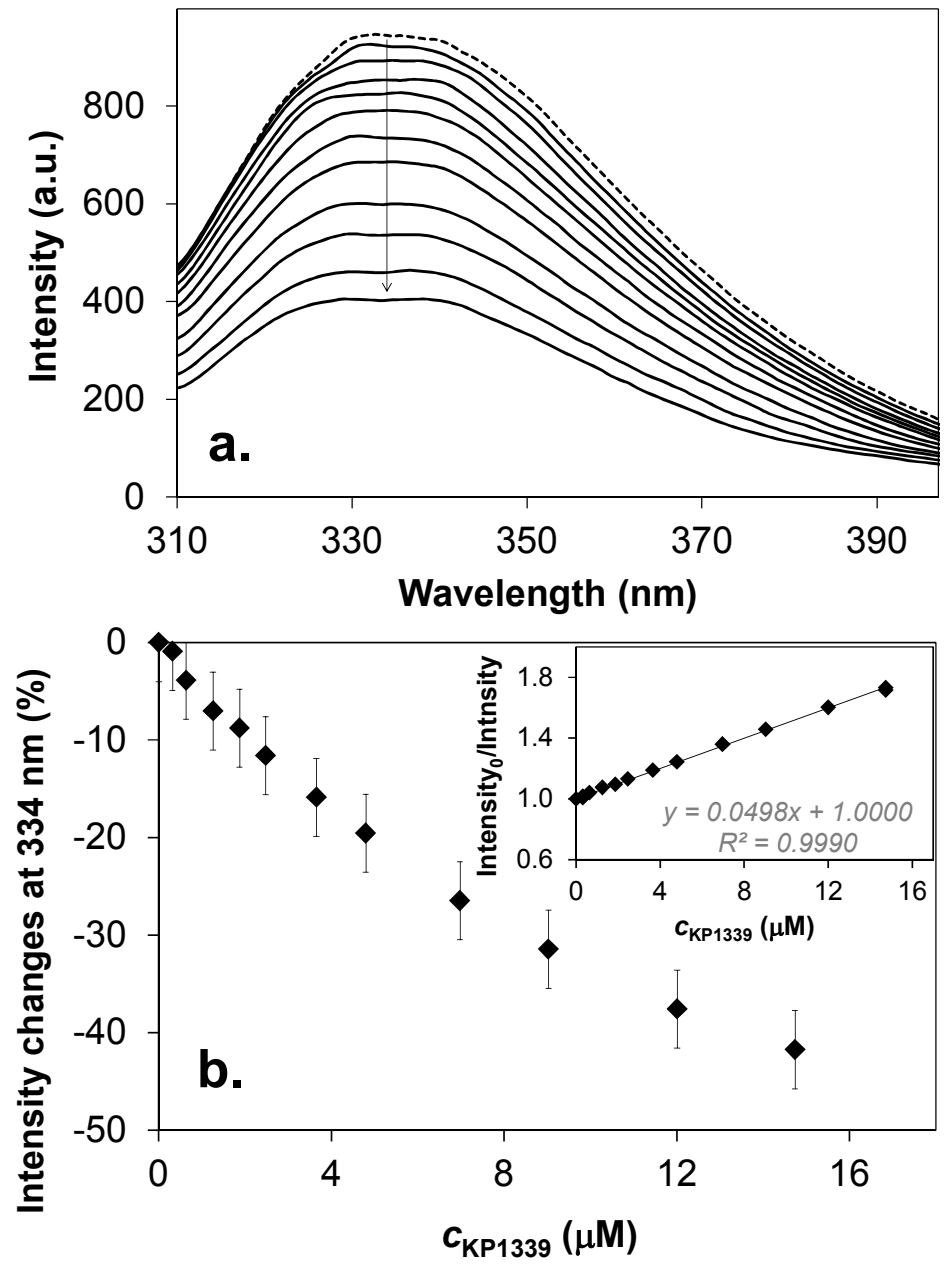

Fig. 1 


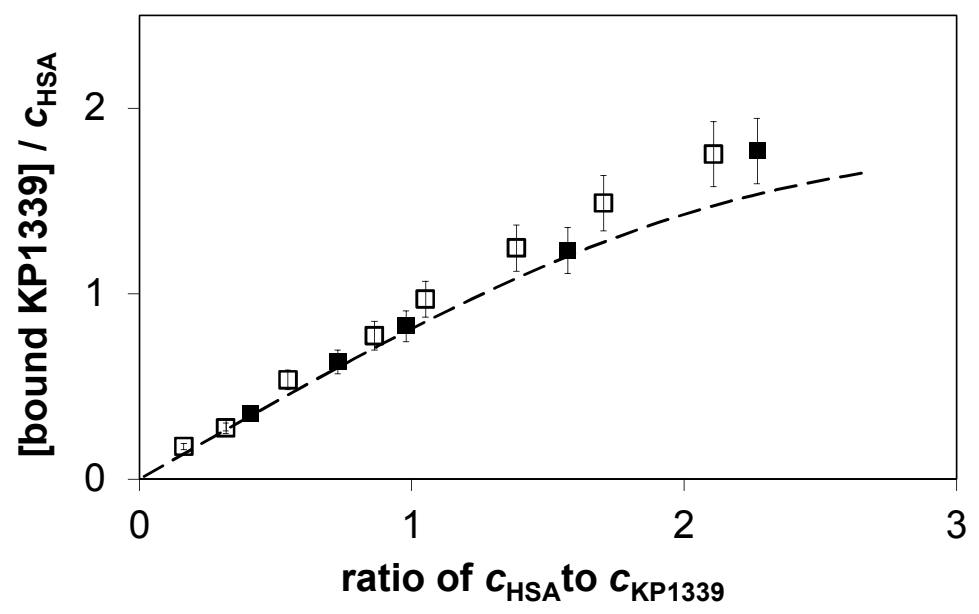

Fig. 2

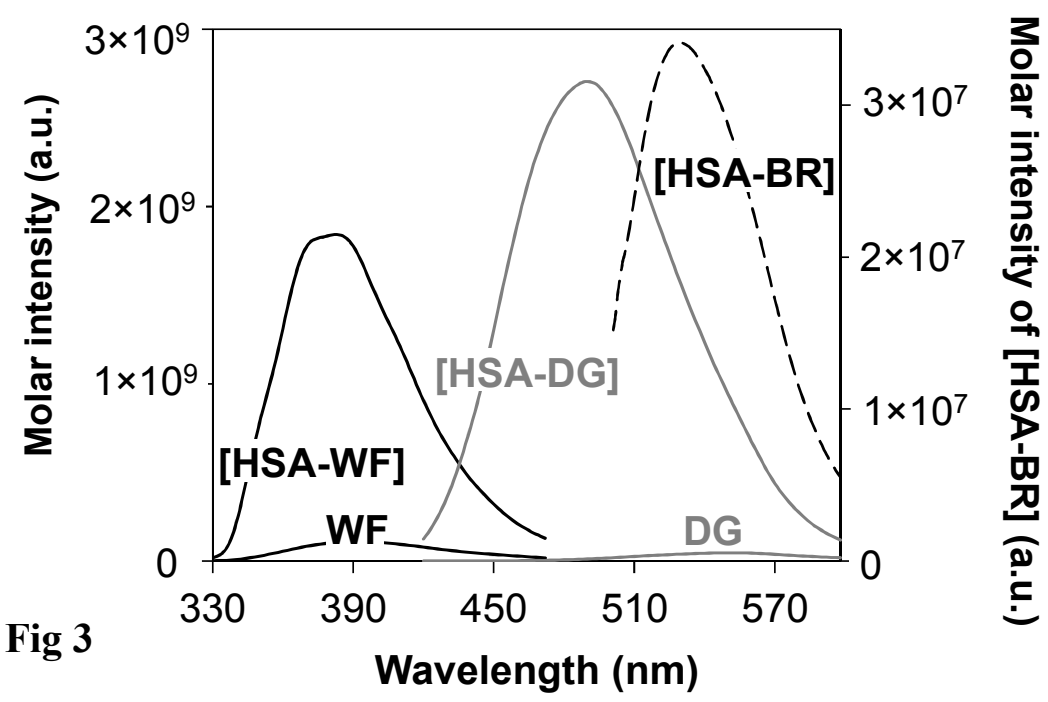




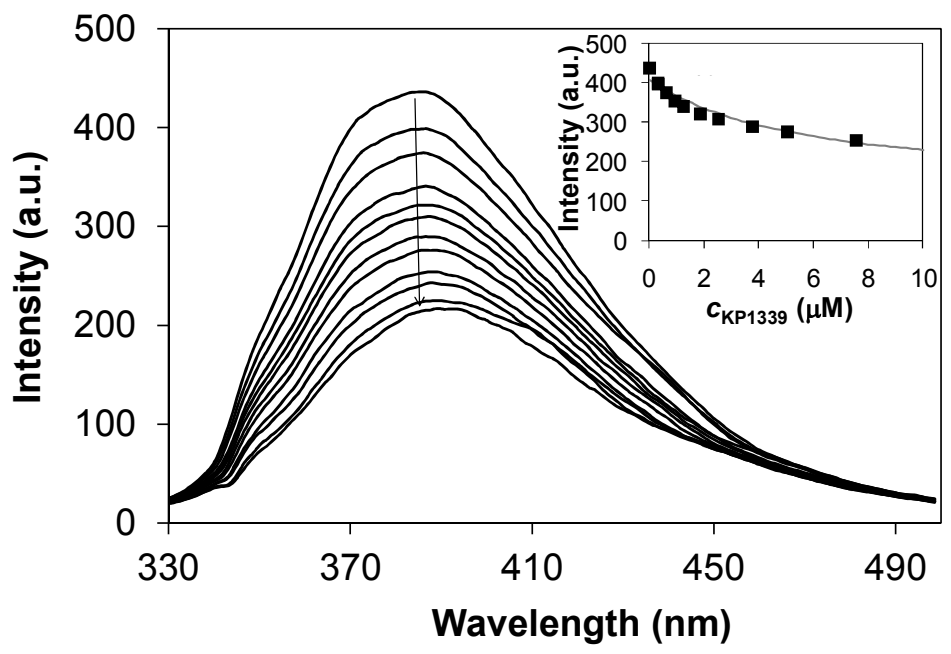

Fig. 4

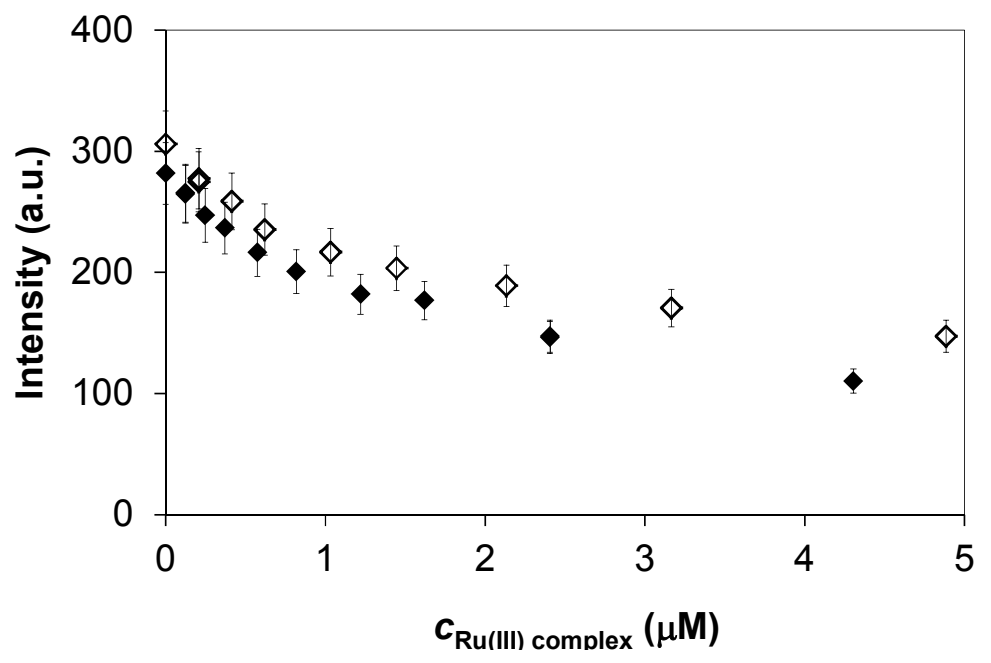

Fig. 5 


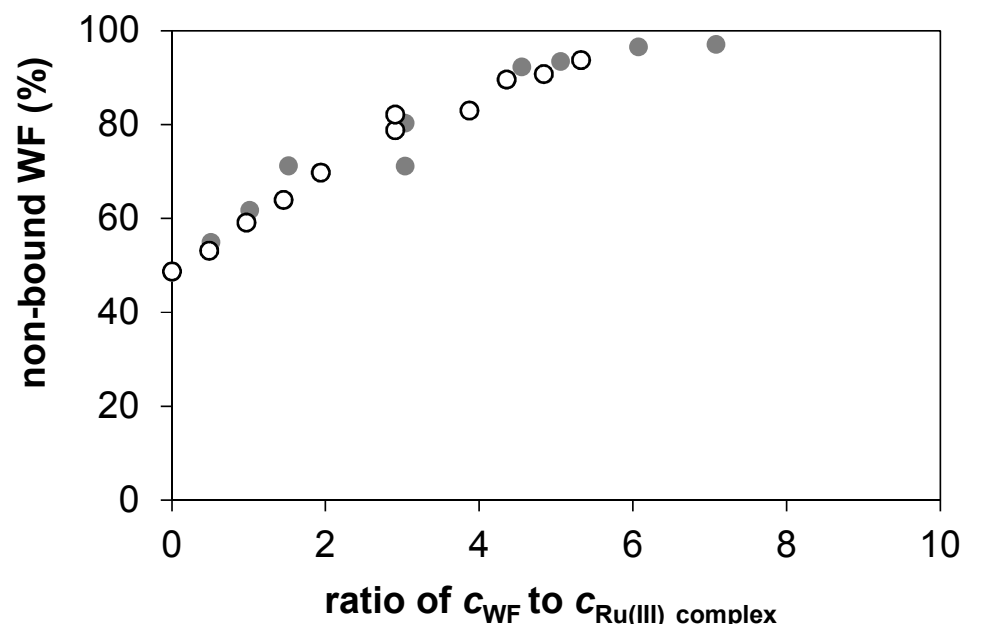

Fig. 6

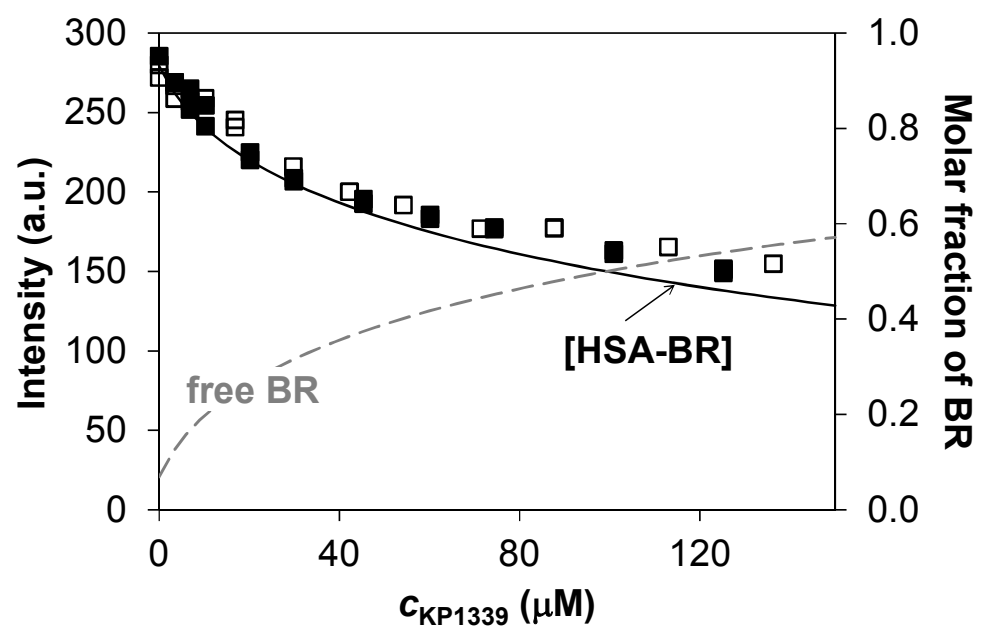

Fig. 7 


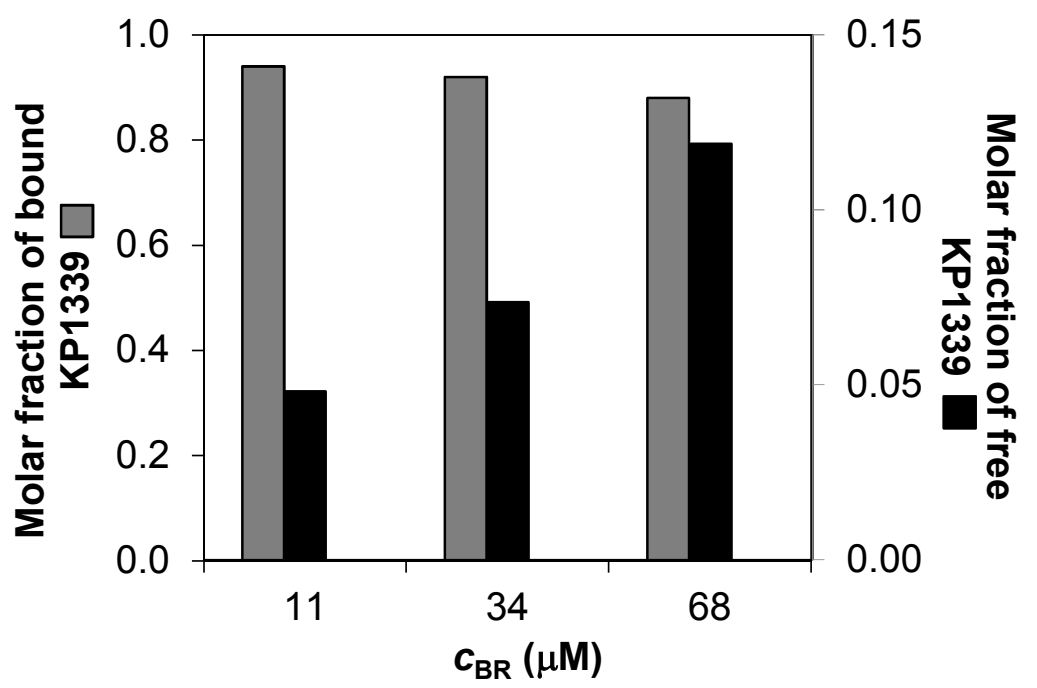

Fig. 8 